\title{
Cardiovocal syndrome
}

\author{
A. Srinivasan 1 , R. Agarwal2
}

A 70-year old gentleman presented with history of hoarseness of voice of six months duration. On examination the heart rate was 96 beats/minute, respiratory rate 18 breaths/ minute and blood pressure was 170/100 mm $\mathrm{Hg}$. Examination of other systems was unremarkable. Indirect laryngoscopy revealed left vocal cord palsy. Chest radiograph done to exclude mediastinal abnormality revealed a paraaortic, homogenous, well defined opacity (figure 1). Contrast enhanced computed tomography was suggestive of a pseudoaneurysm at level of the aortic arch (figure 2). A final diagnosis of cardiovocal syndrome secondary to aortic pseudoaneurysm was made.

The left vagus nerve after entering the neck from the jugular foramen runs in the carotid sheath between the vein and the artery, and then

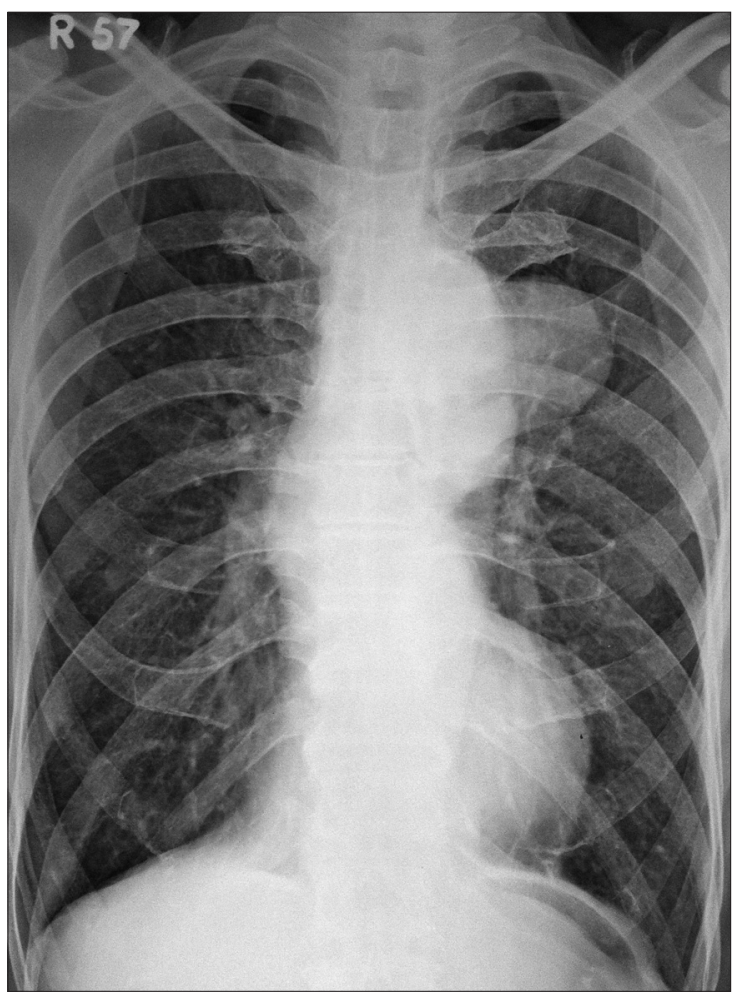

Fig. 1. - Chest radiograph showing a well-defined opacity in the paraaortic location. descends into the superior mediastinum between the left common carotid and subclavian arteries before traversing the left side of the aortic arch. The left recurrent laryngeal nerve arises from the left vagal trunk on the left of the arch of aorta, and winds below the aorta at the point where the ligamentum arteriosum is attached, and then ascends to the side of the trachea in the tracheoesophageal groove.

In 1897, Norbert Ortner described hoarseness of voice secondary to left atrial enlargement causing compression of left recurrent laryngeal nerve in three cases of mitral stenosis [1]. Ortner's syndrome is now considered as left recurrent laryngeal nerve palsy resulting from any cardiovascular disease. The term cardiovocal syndrome was first comprehensively described in English journal by Stocker and Enterline [2]. Although initially described in patients with mitral stenosis, Ortner's syndrome has been reported with a myriad of cardiovascular causes [3]

Aortic pseudoaneurysm is a rare cause of Ortner's syndrome, and is due to compression of the nerve between the aorta and pulmonary artery within the aortic window. The probability of recovery depends on the degree and duration of the neural injury. Till date a total of 30 cases (including the index case) have been de-

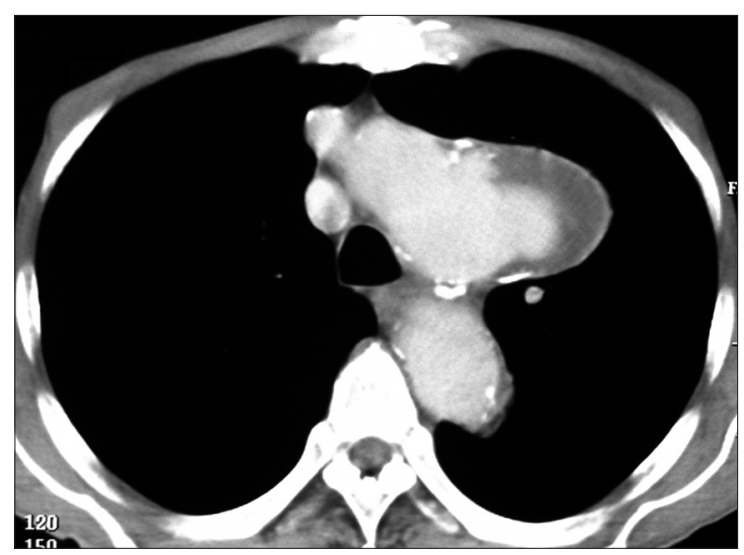

Fig. 2. - Computed tomography showing a pseudoaneurysm at the level of aortic arch.
Monaldi Arch Chest Dis 2011; 75: 4, 241-242

Keywords:

Aortic aneurysm,

Ortner's syndrome,

Recurrent laryngeal

nerve palsy, Mitral

stenosis, Lung cancer,

Cardiovocal syndrome.

1 Senior Resident,

2 Associate Professor,

Department

of Pulmonary Medicine,

Postgraduate Institute

of Medical Education

and Research,

Chandigarh, India.

Correspondence:

Dr Ritesh Agarwal,

Associate Professor

Department

of Pulmonary Medicine,

Postgraduate Institute

of Medical Education

and Research, Sector-12,

Chandigarh-160012, India;

e-mail:

riteshpgi@gmail.com

agarwal.ritesh@pgimer.edu.in 
scribed in the medical literature [4]. Of the cases reported, the most common cause was trauma accounting for 16 of the 30 cases. To the best of our knowledge, there is no case report of spontaneous pseudoaneurysm of aorta causing Ortner's syndrome till date.

These patients are managed by either surgical repair of the pseudoaneurysm or endovascular stenting. The hoarseness improves over the next six weeks to six months in majority of the cases [5]. If there is evidence of either aspiration at presentation or failure of recovery of voice after management of the pseudoaneurysm, the patient can be taken up for vocal cord 'medialization'. The physiological basis of 'medialization' is that it narrows the glottic space, which allows approximation of the cords during phonation allowing the normal vocal cord to make contact with the paralyzed one. Vocal cord medialization can be done either through an endoscopic approach (injection techniques) or externally by means of a cervicotomy to insert an implant [3]. Speech therapy is used as an adjunct and per se is controversial in the management of recurrent laryngeal nerve palsy.

Our index patient was referred to the cardiology department for endovascular stenting but the patient refused any intervention.

\section{References}

1. Ortner N. Recurrenslahmung bei mitralstenose. Wien Klin Wochenschr 1897; 10: 753-5.

2. Stocker HH, Enterline HT. Cardio-vocal syndrome: laryngeal paralysis in intrinsic heart disease. Am Heart J 1958; 56: 51-9.

3. Mulpuru SK, Vasavada BC, Punukollu GK, Patel AG. Cardiovocal syndrome: a systematic review. Heart Lung Circ 2008; 17: 1-4.

4. Yuan SM, Jing H. Cardiovocal syndrome secondary to an aortic pseudoaneurysm. VASA Zeitschrift fur Gefasskrankheiten Journal for Vascular Diseases 2009; 38: 382-9.

5. van Melle JP, Meyns B, Budts W. Ortner's syndrome, presentation of two cases with cardiovocal hoarseness. Acta Cardiol 2010; 65: 703-5. 